\title{
Multiphysics Model Development and the Core Analysis for In Situ Breeding and Burning Reactor
}

\author{
Shengyi Si \\ Shanghai Nuclear Engineering Research \& Design Institute, 29 Hongcao Road, Shanghai 200233, China \\ Correspondence should be addressed to Shengyi Si; jacksi168@gmail.com
}

Received 13 November 2012; Accepted 19 February 2013

Academic Editor: Wei Shen

Copyright (c) 2013 Shengyi Si. This is an open access article distributed under the Creative Commons Attribution License, which permits unrestricted use, distribution, and reproduction in any medium, provided the original work is properly cited.

\begin{abstract}
The in situ breeding and burning reactor (ISBBR), which makes use of the outstanding breeding capability of metallic pellet and the excellent irradiation-resistant performance of $\mathrm{SiC}_{\mathrm{f}} / \mathrm{SiC}$ ceramic composites cladding, can approach the design purpose of ultralong cycle and ultrahigh burnup and maintain stable radial power distribution during the cycle life without refueling and shuffling. Since the characteristics of the fuel pellet and cladding are different from the traditional fuel rod of ceramic pellet and metallic cladding, the multiphysics behaviors in ISBBR are also quite different. A computer code, named TANG, to model the specific multiphysics behaviors in ISBBR has been developed. The primary calculation results provided by TANG demonstrate that ISBBR has an excellent comprehensive performance of GEN-IV and a great development potential.
\end{abstract}

\section{Introduction}

After 60 years of development and deployment, nuclear energy has become one of the three main energy sources supporting human society. Although it happened to three major nuclear accidents during past decades and projected a big shadow on the nuclear energy development, especially the Fukushima Nuclear Event, occurred in March, 2011, significantly twisted people's understanding to nuclear safety, but, people still could not stop 1 the prospects on nuclear energy, as the fossil energy on earth is gradually drying up and increasingly expensive, and the other renewable energy is not enough stable and reliable. By now, except for a few European countries, who claim to terminate their nuclear power projects, the main energy consumers of the world, including China and the United States, have clearly declared their positive position to their established nuclear power route, and several new projects just have been approved during the past recent years.

However, it should be pointed out that the existing nuclear power technology could not support the sustainable nuclear energy development for long-term prospects. The reason is that the existing nuclear power technology is mainly based on water-cooled reactor. It is well known that the fuel utilization of water-cooled reactor is less than $1 \%$, which means that the existing water-cooled reactors are quickly consuming the limited natural uranium resource and producing the huge volume of depleted uranium in front end and the high radioactive spent fuel in back end. According to the 2009 edition of the IAEA red book [1], the natural uranium reserves (including proven and inference) on the earth are about 3.7 million tons (development costs $<\$ 80 / \mathrm{kgU}$ ) or 4.5 million tons (development costs $<\$ 130 / \mathrm{kgU}$ ), and the global natural uranium consumption in 2011 is about 70000 tons [2]; at this rate, the existing nuclear development way can only maintain around 50 years. Furthermore, along with the gradual expansion of global nuclear energy, natural uranium demand is expected to rise steadily to 100000 tons/year in 2015 year [2]. On the other hand, it is approximately estimated that the nuclear development during past 60 years has consumed around 2.8 million tons of natural uranium and produced about 2.5 million tons of depleted uranium and 0.25 million tons of high radioactive spent fuel. Therefore, it is clear that the existing nuclear power technology cannot guarantee a sustainable nuclear development.

In fact, the international society has long known the limitation of the existing nuclear energy technology and has been actively looking for effective ways to pursue the sustainability 
for nuclear development. Among them, a general consensus is that fuel breeding and closed fuel cycle are the crucial options to realize sustainable nuclear energy development. As is well known, fast reactor or harden spectrum is the necessary condition to achieve fuel breeding for current uraniumplutonium fuel cycle, whereas it seems a little optimistic if we think that the existing fast reactor technology is just the solution to the sustainable issue. Taking the existing sodiumcooled fast reactor (SFR) adopting oxide fuel as an example, the one year or so of the refueling cycle brings not only heavy burden of reprocessing and a significant increase in the fuel cycle cost, but also the 20 to 25 years of doubling time seems to give people a choking sense. In recent years, Terra Power LLC, which is founded by Bill Gates, proposed an innovative concept of traveling wave reactor (TWR), which is based on the platform of pool-type sodium-cooled fast reactor by using metallic fuel pellet and HT9 cladding; TWR can approach 30 40 years of ultralong cycle life and around 30 at $\%$ of ultrahigh burnup without refueling, but with periodical fuel shuffling during the cycle life. Theoretically, the TWR can well satisfy the need of sustainable nuclear power development, whereas, because the TWR core is composed of igniting region of medium-enriched uranium and blanket region of depleted uranium, the core radial power distribution shall become severely heterogeneous and have significant variation during the cycle life, and also the ultrahigh burnup shall pose a big challenge to the dose limitation of the HT9 cladding. Therefore, there are still a series of questions for TWR's engineering implementation.

Based on the above understanding, this paper proposed an innovative concept of in situ breeding and burning reactor (ISBBR), which is based on the platform of traditional sodium-cooled fast reactor (SFR), and can approach ultralong cycle and ultrahigh burnup and maintain stable radial power distribution during the cycle life without refueling and shuffling. A computer code TANG modeling main multiphysics phenomenon in ISBBR has been developed for the core design balance. The primary calculation results provided by TANG demonstrate that ISBBR has an excellent comprehensive performance of GEN-IV and a great development potential.

\section{The In Situ Breeding and Burning Reactor}

Obviously, the prerequisites to approach in situ breeding and burning are that the fuel should have great breeding capability and the fuel reactivity should change very slowly during the cycle life. Figures 1 and 2 present the evolution of reactivity and normalized ${ }^{239} \mathrm{Pu}$ versus fuel burnup for several typical fuel materials, which are designed to have similar initial reactivity. It is clear to see that the ternary alloy of Uranium-Plutonium-Zirconium has good attributes matching the demand of ISBBR.

In addition, in order to ensure the integrity of the fuel rod under the conditions of ultralong cycle and ultrahigh burnup, the ISBBR's structure material, especially the fuel cladding material, should have outstanding radiation resistant performance besides the better heat conduction

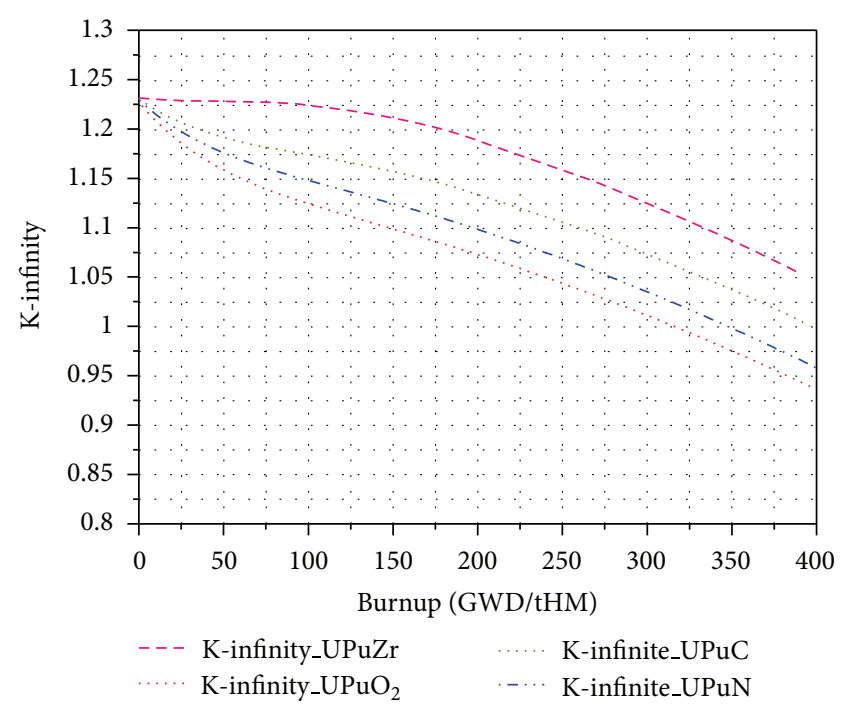

FIGURE 1: Reactivity versus burnup for typical fuel materials.

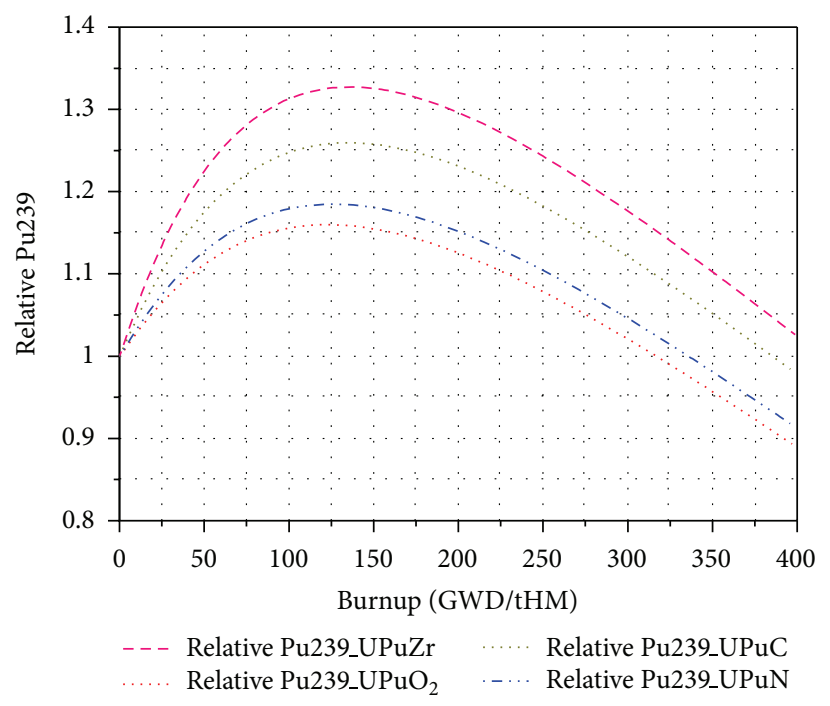

FIgURE 2: Normalized ${ }^{239}$ Pu versus burnup for typical fuel materials.

capability and mechanical performance. The cladding material of the traditional sodium-cooled fast reactor (SFR) is Austenite or Martensite Stainless Steel, whose radiationresistant performance is not enough promising. Some new structure materials under developing, such as ODS and HT9, are predicted to have good radiation-resistant capability; however, it is difficult to have a revolutionary solution because these materials are still iron based. Recently, an innovative ceramic composite material $\mathrm{SiC}_{\mathrm{f}} / \mathrm{SiC}$ has been causing more and more attention from the nuclear field because of its comprehensive performance of heat conduction, mechanical properties, and radiation resistant. It is said that $\mathrm{SiC}_{\mathrm{f}} / \mathrm{SiC}$ is the most promising for the first wall material in fusion reactor [3]. Figures 3 and 4 present the comparison of DPA cross section and radiation dose for $\mathrm{SiC}_{\mathrm{f}} / \mathrm{SiC}$ and stainless steel; 


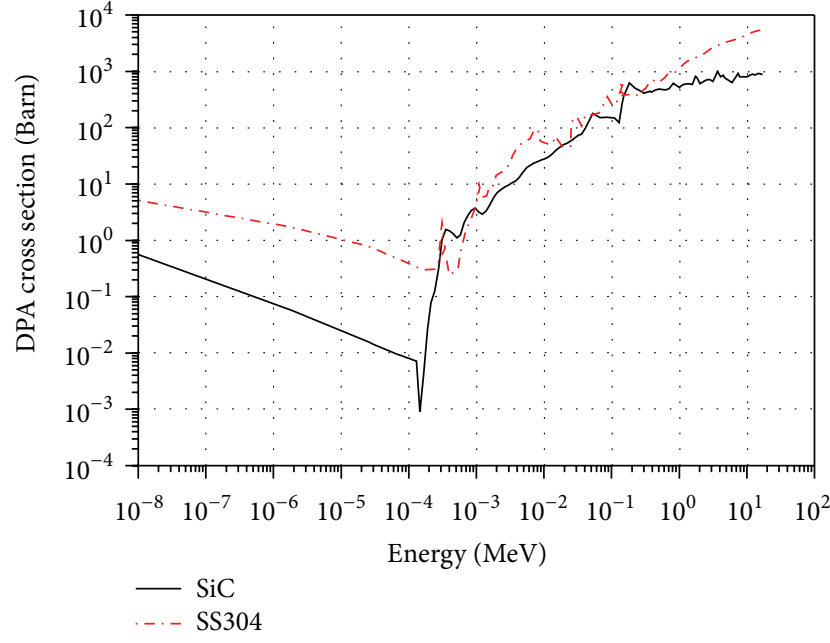

Figure 3: DPA cross section for stainless steel and $\mathrm{SiC}_{\mathrm{f}} / \mathrm{SiC}$.

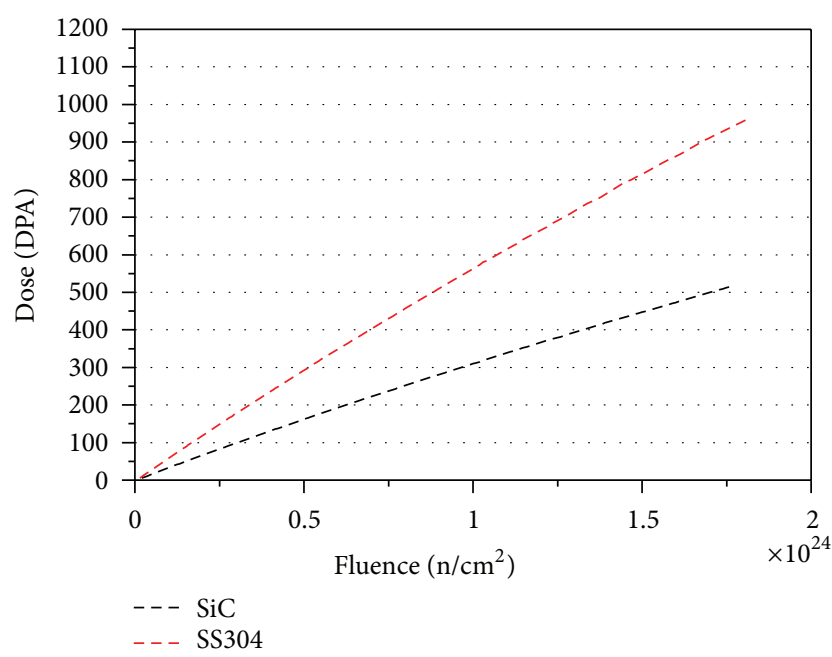

FIgURE 4: DPA dose for stainless steel and $\mathrm{SiC}_{\mathrm{f}} / \mathrm{SiC}$.

we can see that the DPA cross section of $\mathrm{SiC}$ is much lower than SS304 in lower energy and high energy region, and the accumulated radiation dose of $\mathrm{SiC}$ is much lower than SS304 for a given SFR spectrum.

In the view of the above analysis, our proposed in situ breeding and burning reactor (ISBBR) shall select the ternary alloy of Uranium-Plutonium-Zirconium as fuel pellet, $\mathrm{SiC}_{\mathrm{f}} / \mathrm{SiC}$ as cladding material, and liquid sodium as coolant. Table 1 describes the general design parameters of the reference ISBBR core, and Figure 5 illustrates the schematics of reference core, fuel assembly, and fuel rod.

The reference core is a small modular reactor. The rated thermal power is $800 \mathrm{MWt}$, the rated mass flow rate is $5000 \mathrm{~kg} / \mathrm{Sec}$, and the inlet coolant temperature is $350^{\circ} \mathrm{C}$. The core is composed of 222 fuel assemblies, 30 control assemblies, 270 shielding assemblies, and a barrel. The equivalent diameter of active core is about $252 \mathrm{~cm}$ and the outer diameter of barrel is about $350 \mathrm{~cm}$. The active core is divided into inner zone (108 assemblies, identified with 1 in Figure 6) and
TABLE 1: General parameters for reference core of ISBBR.

\begin{tabular}{|c|c|}
\hline Thermal power, MWt & 800 \\
\hline Electricity power, MWe & 300 \\
\hline Coolant flow rate, $\mathrm{kg} / \mathrm{sec}$ & 5000 \\
\hline Inlet temperature, ${ }^{\circ} \mathrm{C}$ & 350 \\
\hline System pressure, MPa & 0.1 \\
\hline Number of fuel assembly & 222 \\
\hline Number of control assembly & 31 \\
\hline Number of shielding assembly & 270 \\
\hline Flat to flat distance of FA, $\mathrm{cm}$ & $\sim 12.5$ \\
\hline Number of fuel pin in a FA & 60 \\
\hline Fuel rod pitch, cm & 1.50 \\
\hline Fuel rod diameter, $\mathrm{cm}$ & 1.40 \\
\hline Active fuel height, cm & 200 \\
\hline Plenum height, $\mathrm{cm}$ & 200 \\
\hline Cladding material & $\mathrm{SiC}_{\mathrm{f}} / \mathrm{SiC}$ \\
\hline Pellet material & UPuZr \\
\hline Coolant material & Sodium \\
\hline Control absorber material & $\mathrm{B}_{4} \mathrm{C}$ \\
\hline Detail size & Reference Figure 5 \\
\hline Heavy metal inventory in core, ton & 40.4 \\
\hline $\mathrm{DU}\left(0.3 \mathrm{w} / \mathrm{o}^{235} \mathrm{U}\right)$, ton & 35.8 \\
\hline Reactor grade $\mathrm{Pu}$, ton & 4.6 \\
\hline \multicolumn{2}{|l|}{ Composition of $\mathrm{Pu}$} \\
\hline${ }^{238} \mathrm{Pu}(\%)$ & 3.54 \\
\hline${ }^{239} \mathrm{Pu}(\%)$ & 50.94 \\
\hline${ }^{240} \mathrm{Pu}(\%)$ & 22.99 \\
\hline${ }^{241} \mathrm{Pu}(\%)$ & 15.15 \\
\hline${ }^{242} \mathrm{Pu}(\%)$ & 7.38 \\
\hline
\end{tabular}

outer zone (104 assemblies, identified with 2 in Figure 6). The unique difference for the fuel assemblies in inner zone and outer zone is the Zirconium contents in the fuel pellet which are $20 \%$ and $10 \%$, respectively.

The fuel assembly has an overall length of $460 \mathrm{~cm}$ and contains 90 fuel pins arranged in a triangular pitch array within a duct, see Figure 5. The duct thickness is $0.1 \mathrm{~cm}$ and the flat-to-flat distance of the duct is around $12.5 \mathrm{~cm}$. Fuel pins are made of sealed $\mathrm{SiC}_{\mathrm{f}} / \mathrm{SiC}$ cladding containing a metallic fuel pellet column of $200 \mathrm{~cm}$ length. Just below the fuel slug is a $60 \mathrm{~cm}$ shield segment, with the shield being an integral part of the fuel pin in the form of an extended fuel-pin bottom end cap. Sodium is filled as the initial thermal bond between the fuel column and the cladding. And a $200 \mathrm{~cm}$ long fission gas plenum is located above the fuel slug and sodium bond. The fuel pin diameter and cladding thickness are $1.4 \mathrm{~cm}$ and $0.1 \mathrm{~cm}$, respectively, and the inner diameter and outer diameter of the annular pellet are $0.4 \mathrm{~cm}$ and $1.1 \mathrm{~cm}$, respectively. The fuel smeared density is $80 \%$. The fuel pin is helically wrapped with wire to maintain the pin spacing so that the coolant can flow freely through the pin bundle. The wire-wrap helical pitch is $20.32 \mathrm{~cm}$ and the wire diameter is $0.1 \mathrm{~cm}$. 


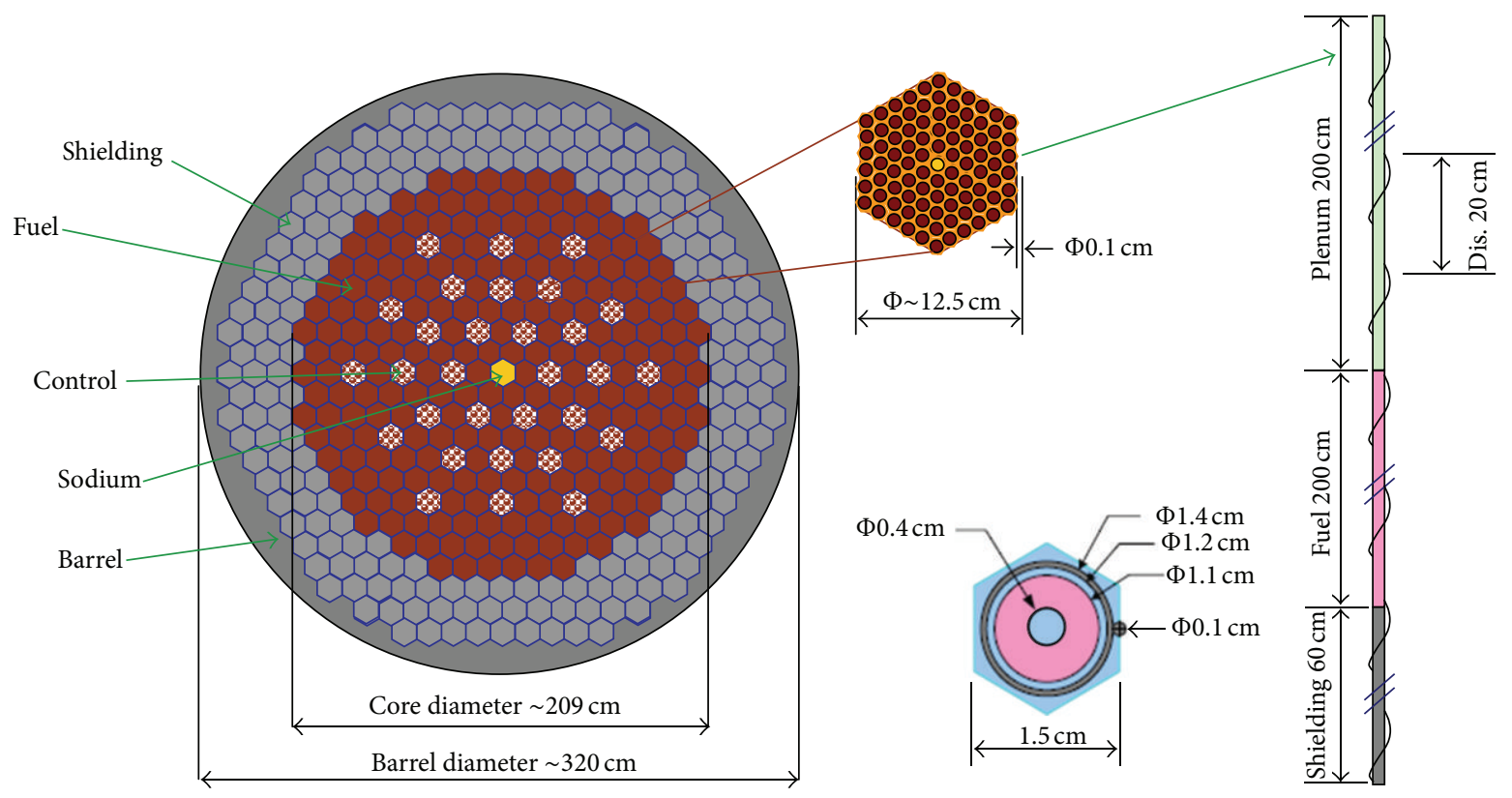

FIGURE 5: Schematic for the reference core of in situ breeding and burning reactor.

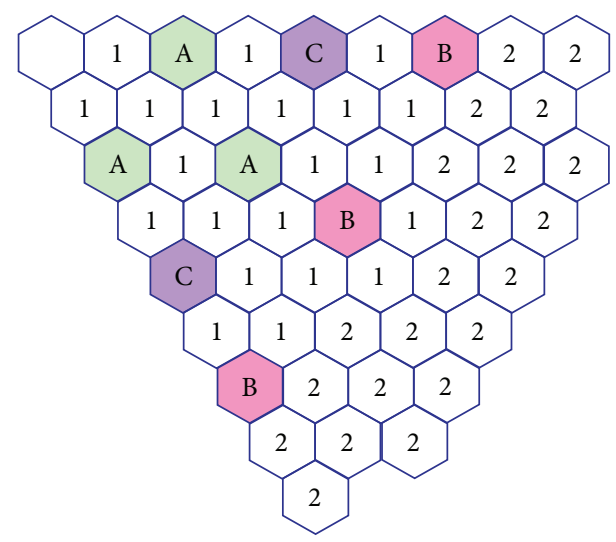

FIGURE 6: Grouping and Layout of Control Assembly.

The control assemblies consist of an absorber bundle contained within a duct. The absorber bundle is a closely packed array of tubes containing compacted boron carbide pellets. The natural boron whose B-10 enrichment is $19.9 \mathrm{a} / \mathrm{o}$ is used. Thirty control assemblies are grouped into A, B, and C banks, where bank $A$ is the primary manipulated bank, bank $\mathrm{B}$ is the secondary control bank, and bank $\mathrm{C}$ is the shutdown bank. The grouping of the control assemblies and its layout are given in Figure 6.

\section{The Multiphysics Model Development for ISBBR}

Traditionally, nuclear design, thermal-hydraulic analysis, and fuel performance analysis for a reactor core are performed independently. Actually, the neutronics behavior, thermalhydraulic behavior, fuel thermodynamics behavior, and fuel irradiation behavior in a reactor core are tightly coupled with each other. In PWR core design, thermal-hydraulic feedback has been considered widely in core analysis code due to the significant spectrum effect of coolant density and Doppler effect of fuel temperature. As for ISBBR, besides the thermalhydraulic feedback, the reactivity effect of thermal expansion and irradiation swelling also have significant influence on the core reactivity and the cycle life.

Figure 7 illustrates the main physics phenomena in the core using metallic fuel. Basically, the neutronics process (Cross Section Parameter $\rightarrow$ Diffusion/Transport Solution $\rightarrow$ Neutron Flux $\rightarrow$ Reaction Rate $\rightarrow$ Burnup $\rightarrow$ Cross section Parameter, see Figure 7) is the main driving force for the multiphysics phenomena in the core. Generally, the interactions of neutronics with other disciplines can be grouped into instant effect and historical effect. As for the instant coupling effect, power density derived from the reaction rate determines the fuel rod surface heat flux and the coolant flow field (coolant density and temperature), and also, the power density dominates the fuel temperature distribution in pellet. On the other hand, the coolant density and temperature and fuel temperature and the fuel thermal expansion have direct influence on the cross section parameter, neutron flux, and power density. As for the historical accumulation effect, the accumulated neutron irradiation connects to the fuel burnup, deformation (creep and swell) of cladding and pellet, and fission gas release; all these effects will have influence on the local reaction cross section; in addition, the deformation of cladding and pellet affects the free volume of the fuel rod plenum, which has inversely proportional relations with the rod internal pressure. 


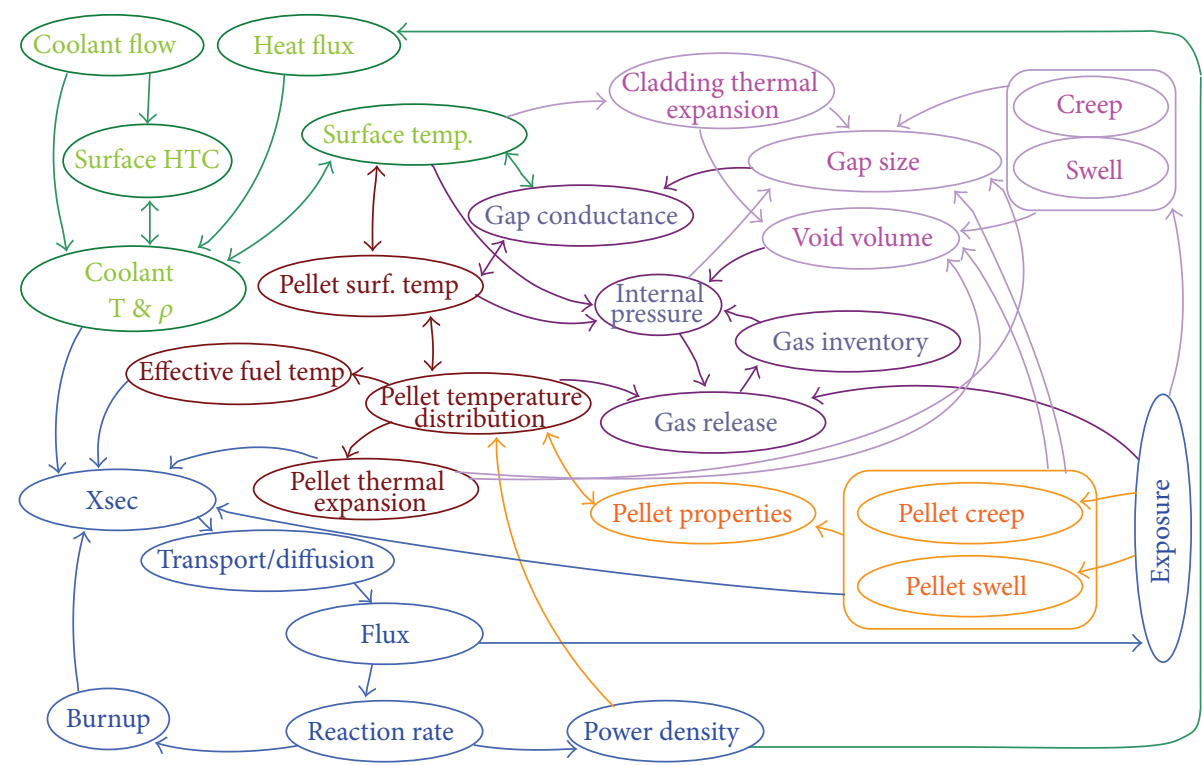

FIgURE 7: Multiphysics behaviors for the core with metallic fuel.

Based on the understanding to the above multiphysics phenomena in the core using metallic fuel and the specific ISBBR fuel design of metallic pellet and ceramic cladding, we developed the specific multiphysics model and the core simulation code TANG for ISBBR. The following sections briefly describe the technical characteristics of the multiphysics model and computer code TANG.

3.1. Neutronics Model. Neutronics model is the kernel of multiphysics model and also the driving force for heat conduction, heat transfer, and deformation of fuel rod. Neutronics model involves depletion model, parameterized cross section model, and multidimension/multigroup neutron diffusion model.

The depletion model solves nonlinear depletion chains by using Matrix Exponential Algorithm and tracks the evolution of nodal-wise number density for major actinides based on the $3 \mathrm{D}$ neutron flux and reaction rate during full cycle life. Figure 8 presents the simplified depletion chain for actinides tracked in TANG code.

Parameterized cross section model captures the instant effect and historical effect of various factors on homogenized assembly cross sections. The instant effect is caused by the deviation of instant local conditions from the reference conditions, such as local burnup (bu), local coolant temperature/density $\left(D_{c} / T_{c}\right)$, local fuel temperature $\left(T_{f}\right)$, and local axial deformation factor $(\alpha)$, and the historical effect is the accumulated effect caused by the long-term deviation of local conditions from the reference conditions since the deviation of local conditions causes the different local neutron spectrum from the reference case, it results in the different depletion rate or production rate for important actinides from the reference case. The local axial deformation factor $(\alpha)$ models the effect of number densities variation caused by axial deformation on homogenized assembly cross sections. The formula (1) gives the fundamental expression of the parameterized cross section model:

$$
\begin{aligned}
& \sum\left(\mathrm{bu}, T_{f}, D_{c}, \alpha\right) \\
& =\frac{\sum_{\mathrm{ref}}(\mathrm{bu})+\Delta \sum\left(\mathrm{bu}, T_{f}, D_{c}\right)+\sum_{n}^{N} \sigma_{n}\left(T_{f}, D_{c}\right) \Delta N_{n}}{\alpha} .
\end{aligned}
$$

Multidimension/multigroup neutron diffusion model adopts multidimension and multigroup nodal expansion method code MGNEM [4], developed by author previously, to solve multidimension and multigroup neutron diffusion equations for rectangular and hexagonal fuel assembly; also, the universal algorithm of stiffness confinement method (UASCM) [5], which was also developed by author earlier, is coupled with MGNEM to solve multidimension and multigroup timespace kinetic problem. Additional, in order to effectively model the growth of nodal axial mesh caused by thermal expansion and/or irradiation swelling, MGNEM code is using floating mesh in axial direction, so that MGNEM is able to automatically model the axial mesh variation of each node during the iteration process of thermal-hydraulic feedback and finally captures the reactivity effect of axial deformation.

The integration of the above methodologies and technologies endows TANG code abundant calculation functions and flexible simulation ability.

3.2. Fuel Rod Deformation Model. The thermal expansion coefficient of metallic fuel is large (approximately 2 times of ceramic fuel), and the irradiation swelling effect of metallic fuel is also significant (around 30\% at high burnup). As a result, the geometrical change of metallic fuel pellet during heating process and/or irradiation process will not only give penalty on the extra reactivity and cycle life of the core, but also will directly affect the transient behavior of the 


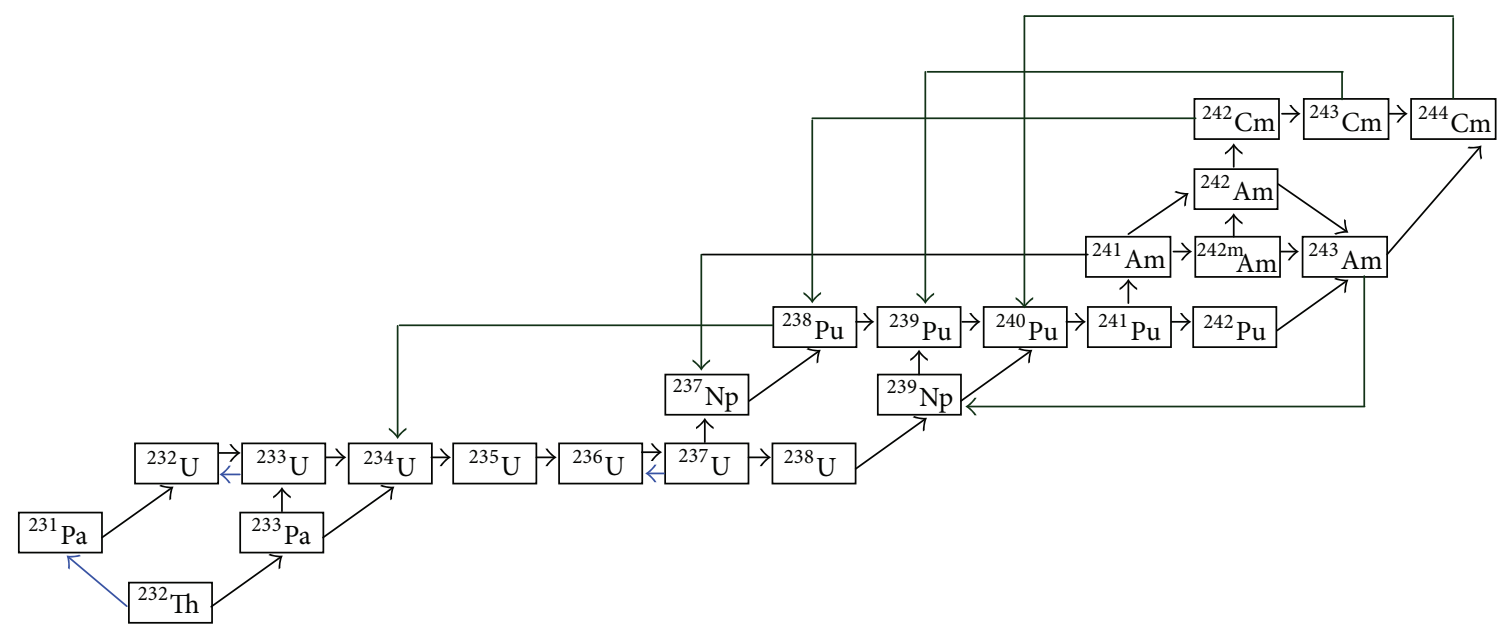

FIGURE 8: Depletion chain for actinides tracked in TANG code.

core, as the negative feedback effect of axial growth can effectively restrain the increase of the reactor core power and automatically bring the reactor to a safe lower power level. The experiments on EBR-II had demonstrated this inherent safety characteristic of the core with metallic fuel [6].

Relative to the metallic pellet, the $\mathrm{SiC}_{\mathrm{f}} / \mathrm{SiC}$ cladding has very good thermal stability, irradiation stability, and mechanics stability. Firstly, the thermal expansion coefficient of $\mathrm{SiC}_{\mathrm{f}} / \mathrm{SiC}$ is only about half of the zircaloy; secondly, the existing irradiation experiment (about $43 \mathrm{DPA}$ ) shows that the swelling and creeping phenomena are very weak [3]; in addition, since the strength and hardness of $\mathrm{SiC}_{\mathrm{f}} / \mathrm{SiC}$ are very outstanding, the strain caused by stress for $\mathrm{SiC}_{\mathrm{f}} / \mathrm{SiC}$ material is also very limited. Table 2 presents the properties of relative materials.

According to the above analysis on the metallic pellet and $\mathrm{SiC}_{\mathrm{f}} / \mathrm{SiC}$ ceramic cladding, we proposed a "rigid cladding model" to describe the fuel rod deformation behavior in ISBBR, which assumes the following.

(i) The deformation of $\mathrm{SiC}_{\mathrm{f}} / \mathrm{SiC}$ ceramic cladding is only due to thermal expansion, irradiation swelling, creeping, and stress/strain are ignored.

(ii) The deformation of metallic pellet may be caused by thermal expansion, irradiation swelling, and creeping.

(iii) After the metallic pellet contacts with ceramic cladding, the contact stress shall not cause any strain to ceramic cladding.

(iv) After the metallic pellet contacts with ceramic cladding, the metallic pellet shall become yielded consequently due to the contact stress, and according to the Prandtl-Reuss flow rule, the expansion shall develop to the inner hole of the annular pellet; once the inner hole is closed, the expansion shall switch to axial direction.

Thermal expansion is recoverable and the irradiation deformation (swelling and creeping) is irrecoverable. Therefore,

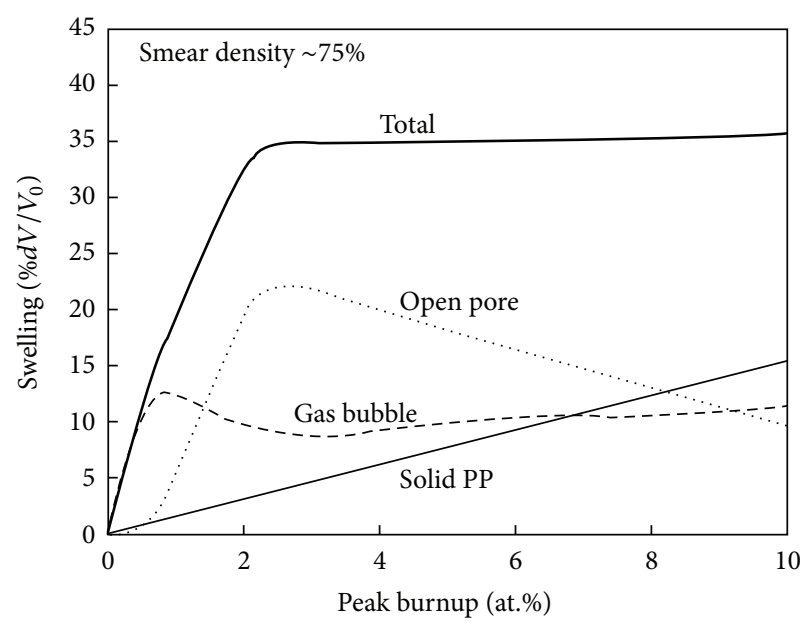

FIGURE 9: Radial swelling versus burnup for metallic fuel.

with the assumption of "rigid cladding model," the cladding deformation is recoverable, and the pellet deformation involves the recoverable and irrecoverable compositions. The recoverable deformation of metallic pellet can affect the core dynamic parameters and the transient behavior of the core, and the irrecoverable deformation of the metallic pellet has direct penalty on the core extra reactivity and the cycle life.

Metallic fuel had significant irrecoverable deformation (swelling and creeping). Figures 9 and 10 present the radial deformation and axial deformation behavior of metallic fuel versus the fuel burnup, respectively, which are based on the experimental results of EBR-II. It can be seen from Figures 9 and 10 that the irradiation deformation of metallic fuel is anisotropic in radial and axial direction; the radial deformation is much more significant than the axial deformation, and the radial deformation grows quickly before 2 at $\%$ burnup, and thereafter it maintains around $35 \%$ of volume change rate. The irradiation deformation models used in TANG code are just taken from Figures 9 and 10 [7]. 
TABLE 2: Properties of several typical fuel materials.

\begin{tabular}{lcccc}
\hline & Thermal expansion coefficient $\mathrm{ppm} /{ }^{\circ} \mathrm{C}$ & Brinell hardness $\mathrm{kg} / \mathrm{mm}^{2}$ & Young's modular $(E) \mathrm{GPa}$ & Poisson's ratio $(\nu)$ \\
\hline UO2 (ceramic) & $\sim 9$ & $\sim 2000$ & $\sim 96$ & $\sim 0.3$ \\
UPuZr (alloy) & $\sim 18$ & $\sim 260$ & $\sim 85$ & $\sim 0.3$ \\
\hline Zircaloy & $\sim 10$ & $\sim 120$ & $\sim 100$ & $\sim 196$ \\
Stainless steel & $\sim 17$ & $\sim 100$ & $\sim 300$ & $\sim 0.3$ \\
SiC $_{\mathrm{f}} / \mathrm{SiC}$ (ceramic) [3] & $\sim 4$ & $\sim 2800$ & $\sim .14$ \\
\hline
\end{tabular}

3.3. Fuel Rods Heat Conduction/Transfer Model. Each fuel assembly in ISBBR is contained within a duct, which directs the coolant flow to fuel rods of the fuel assembly, and there is no exchange of coolant mass and momentum among the assemblies. Therefore, it is reasonable for TANG code to adopt the "single channel model" to simulate the heat conduction within fuel rod and heat transfer between rod surface and coolant; TANG code has a "single channel model" for each fuel assembly modeled in the core to calculate the averaged effect of coolant density/temperature, cladding temperature, and fuel temperature in each elevation of the fuel assembly, and then, the 3D nodal-wise coolant density/temperature, cladding temperature, and fuel temperature are passed to 3D neutronics model, rod deformation model, and other models, so that all models are tightly coupled into a multiphysics model.

The "single channel model" in TANG code uses finite difference method to solve time-dependent heat conduction equation in cylindrical R-Z geometry for steady-state and transient solution, which shall be coupled with steady-state or transient 3D neutronics model. The heat conduction along $z$-direction is considered due to the high heat conductivity of metallic pellet.

The discrete of heat conduction equation is based on the nominal rod sizes so as to maintain the stability during equation solution, but the deformed rod sizes are used for the gap conductance calculation.

3.4. Fuel Rod Internal Pressure Model. The fuel rod in ISBBR might endure extra high internal pressure and even endanger the fuel rod integrity due to the fission gas release and accumulation under ultralong cycle and ultrahigh burnup. Therefore, the fuel rod internal pressure in ISBBR is an important design constraint. Based on the "single channel model" and 3D burnup distribution of the core, TANG code tracks the fission gas release fraction for 3D nodes and calculates assembly-averaged fuel rod internal pressure at each burnup step.

The main components of fission gas are $\mathrm{Xe}$ and $\mathrm{Kr}$, and the total fission yield of $\mathrm{Xe}$ and $\mathrm{Kr}$ is about 0.25 (totally $2.0)$. Fission gas is gathered in the grain boundary in earlier stage; with the burnup accumulation, the fission gas gradually gathers into bubble; bubbles grow along with the increased inner pressure and connected mutually; finally, it forms a coherent tunnel. Eventually, fission gas is driven by the temperature and the pressure and release to the gap between pellet and cladding and then the plenum of the rod. The coherent tunnel in metallic fuel is formed at around 2 3 at $\%$

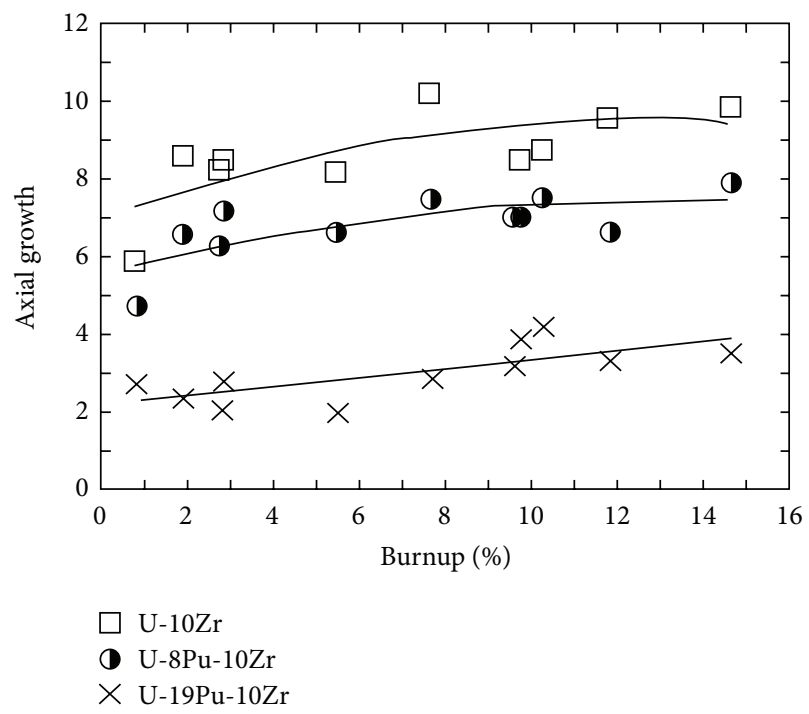

FIgURE 10: Axial swelling versus burnup for metallic fuel.

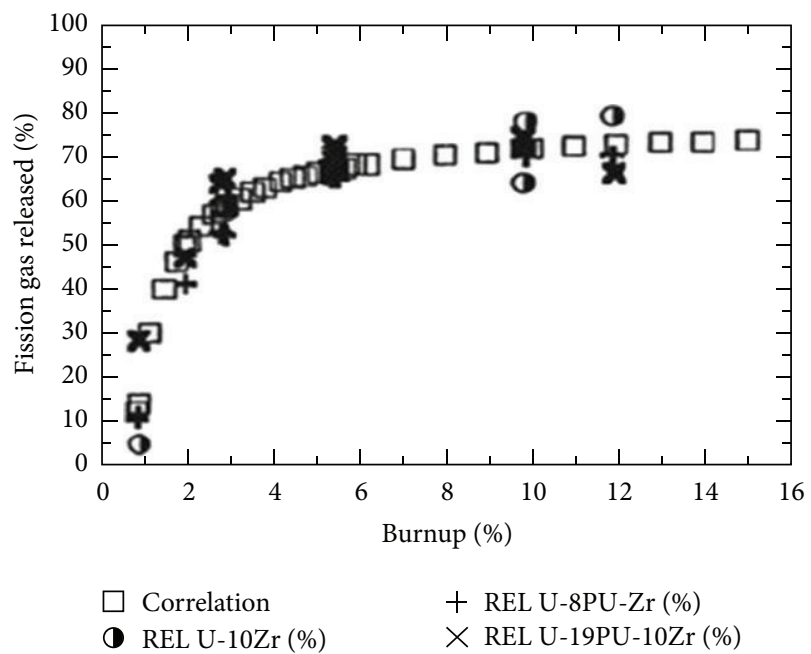

FIGURE 11: Fission gas releases fraction for metallic fuel.

of burnup, the release fraction of fission gas increases quickly prior to 3 at $\%$ of burnup; thereafter, the release fraction maintains at around $70 \%$. Figure 11 presents the fission gas release fraction of metallic fuel versus the fuel burnup, which is based on the experimental results of EBR-II. The fission gas release model used in TANG code is just taken from Figure 11 [7]. 
The fuel rods internal pressure is calculated by using the free gas state equation $P V=M R T$, in which, $P$ is the fuel rods internal pressure; $V$ is the volume of free space in fuel rods, involving the comprehensive effect of the ceramic cladding deformation, metallic pellet thermal expansion, metallic pellet swelling, and the liquid sodium surface rise squeezed by the deformed cladding and pellet; $M$ is the fuel rods internal gas mole number, including the fission gas and the initial fill gas; $R$ is a universal gas constant $(R=8.34 \mathrm{~J} /$ Mole- $\mathrm{K}) ; T$ is the average temperature of the fuel plenum.

3.5. Fuel Rod Exposure Dose Model. The structure material, especially the cladding material, in ISBBR might endure severe radiation damage due to ultralong time exposure of fast neutron spectrum. The radiation damage to material usually is measured by displacement per atom (DPA), which means the accumulative displacement number of each medium atom. TANG code equips a fuel rod exposure dose model, so that the maximum cladding dose can be monitored during core design process.

The multigroup DPA cross sections $\left(\sigma_{g}^{\mathrm{DPA}}\right)$ are stored in the parameterized cross section library as the same as other cross sections expressed in formula (1); TANG code shall evaluate the accumulated cladding dose for each node of core based on the 3D flux solution $\left(\phi_{g}\right)$ and the depletion time increment $(\Delta T, \operatorname{Sec})$ with the following formula:

$$
\mathrm{DPA}^{n+1}=\mathrm{DPA}^{n}+\Delta T \sum_{g} \sigma_{g}^{\mathrm{DPA}} \phi_{g} .
$$

\section{Calculation Results}

The reference ISBBR core was analyzed with TANG code, and the calculation results are introduced in following sections.

4.1. Steady-State Results Analysis. Figure 12 shows the relation of atom burnup and energy burnup for reference ISBBR core during 25 effective full power years (EFPYs); it can be seen that 1 at\% burnup is equivalent to about $10 \mathrm{GWD} / \mathrm{tHM}$ for the reference core; the slight deviation at end of life is due to the fission energy of minor actinide (MA) which is a little higher than plutonium.

Figure 13 presents the critical position of control assembly and the evolution of the peaking power factors during the cycle life. It can be seen from Figure 13 that ISBBR can achieve stable and flat power distribution during the $25 \mathrm{EFPYs}$ of cycle life; Figure 14 further shows the radial power distribution of reference core at different burnup steps and demonstrates that the radial power distribution of reference core is well maintained without shuffling and refueling within an ultralong cycle life. Therefore, ISBBR can avoid the significant distortion and variation of the power distribution existing in other conceptual breeding and burning reactors [8-11]. It is beneficial to core design and power distribution control in engineering sense.

Figure 15 presents the assembly-wise distribution for key design parameters at EOL (25 EFPYs) tracked by the multiphysics models in TANG code. Maximum dose is the

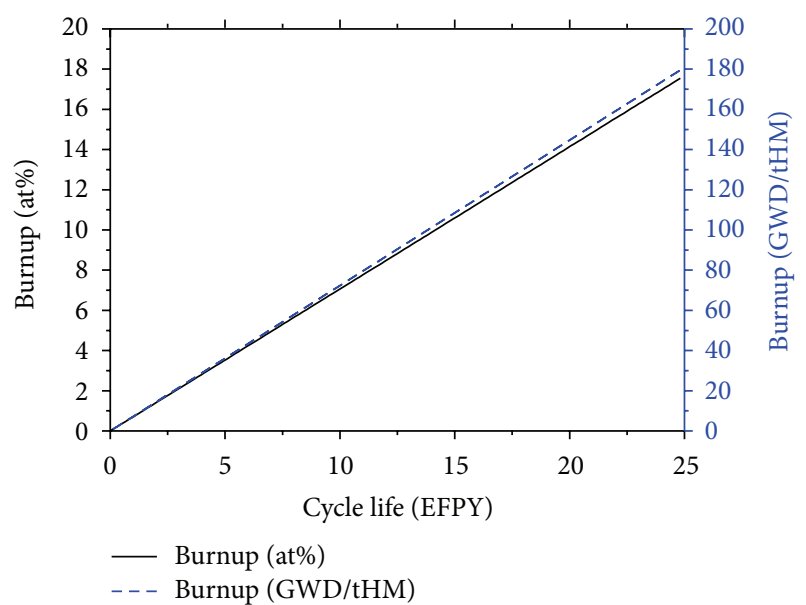

FiguRE 12: Burnup versus cycle length for reference core.

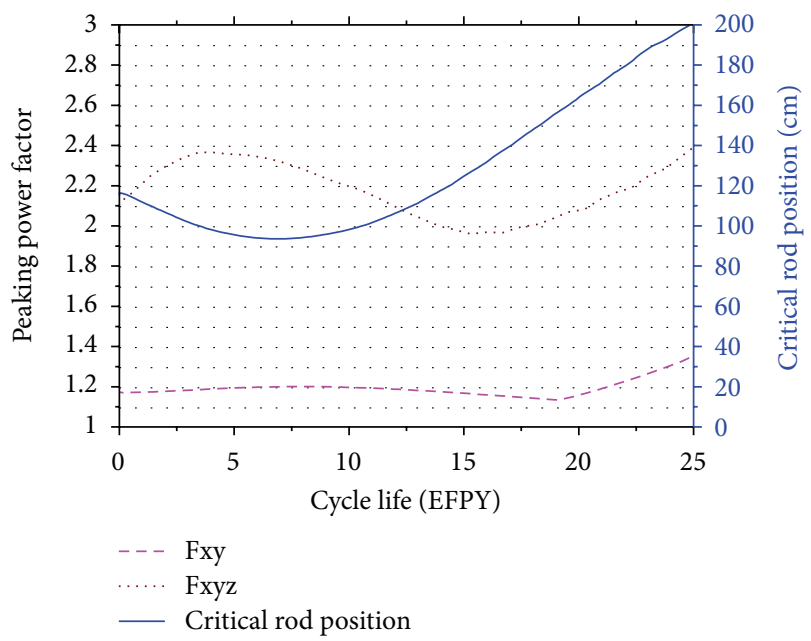

FIGURE 13: Critical rod position and power peaking factor versus cycle lifetime.

peaking irradiation dose for each assembly, and the results show that the maximum irradiation dose at EOL for the $\mathrm{SiC}_{\mathrm{f}} / \mathrm{SiC}$ ceramic cladding in ISBBR core is about $167.8 \mathrm{DPA}$, which is far smaller than that using stainless steel cladding (e.g., for TWR, the peaking irradiation dose may be as high as $500 \mathrm{DPA}$ ); internal pressure is an assembly-averaged rod internal pressure, and the tracked results demonstrate that the maximum internal pressure of fuel rod at EOL in reference core is about $13 \mathrm{MPa}$, which is thought to be safe to the rod integrity according to the experience of PWR rod performance analysis; the axial deformation factor is an assembly-averaged axial deformation factor, and the calculation results show that the axial deformation of the reference core is more balanced among the full core, which means that the annular pellet has accommodated the radial pellet swelling and the axial deformation is mainly composed of thermal expansion and axial swelling. Figure 16 illustrates the influence of axial thermal expansion and swelling on the core reactivity. 


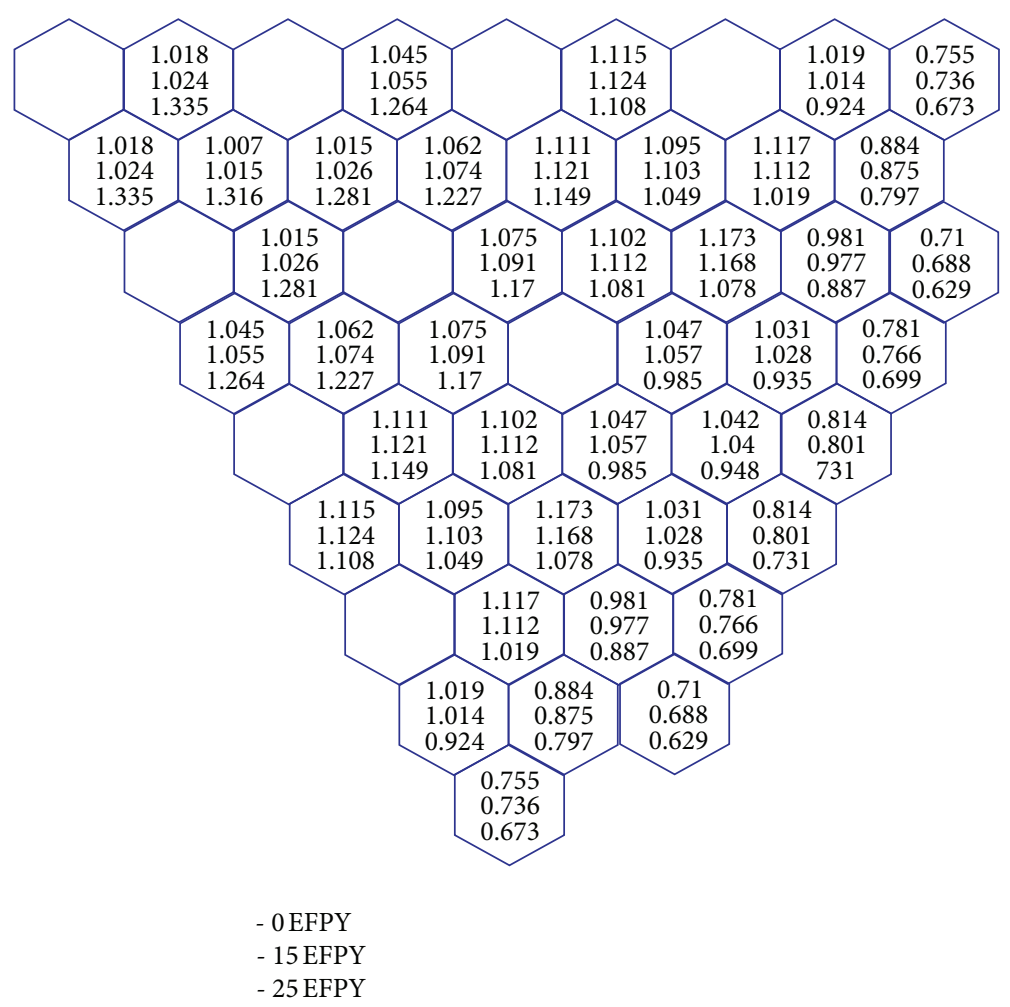

FIGURE 14: Assembly-wise power distribution at 0 EFPY/15 EFPY/25 EFPY.

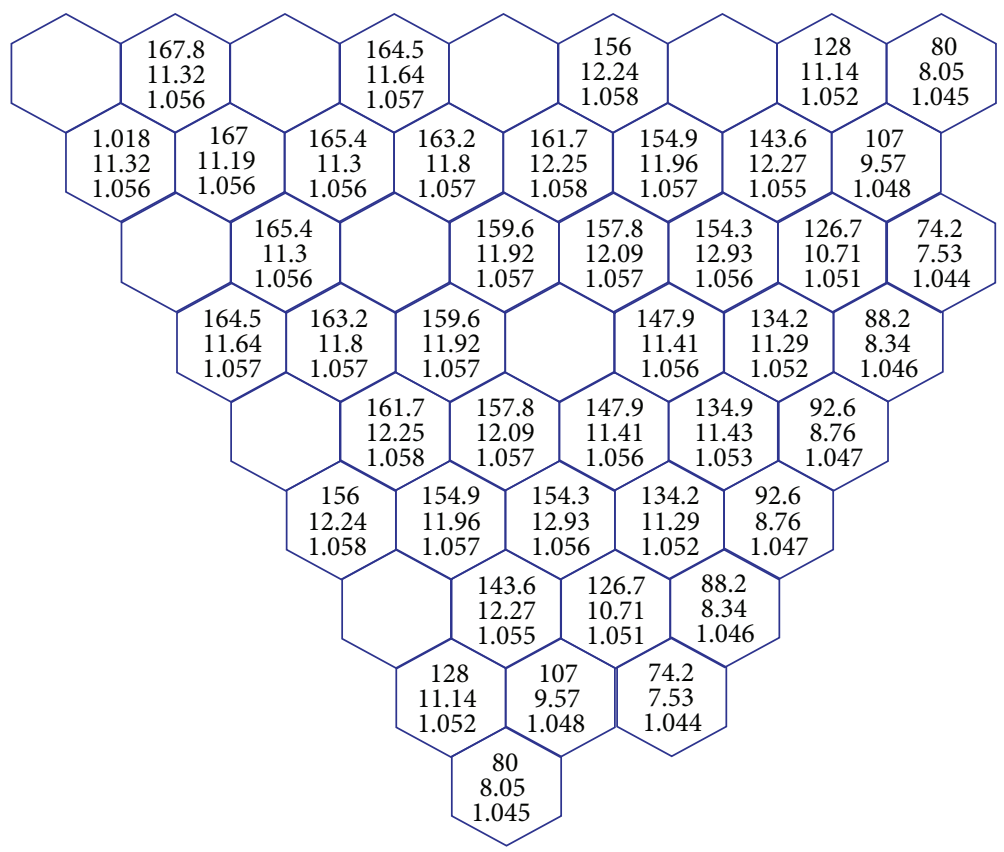

\footnotetext{
- Maximum dose (DPA)

- Internal pressure (MPa)

- Axial deformation factor
}

FIGURE 15: Assembly-wise maximum cladding dose, rod internal pressure, and average axial deformation factor at EOL. 


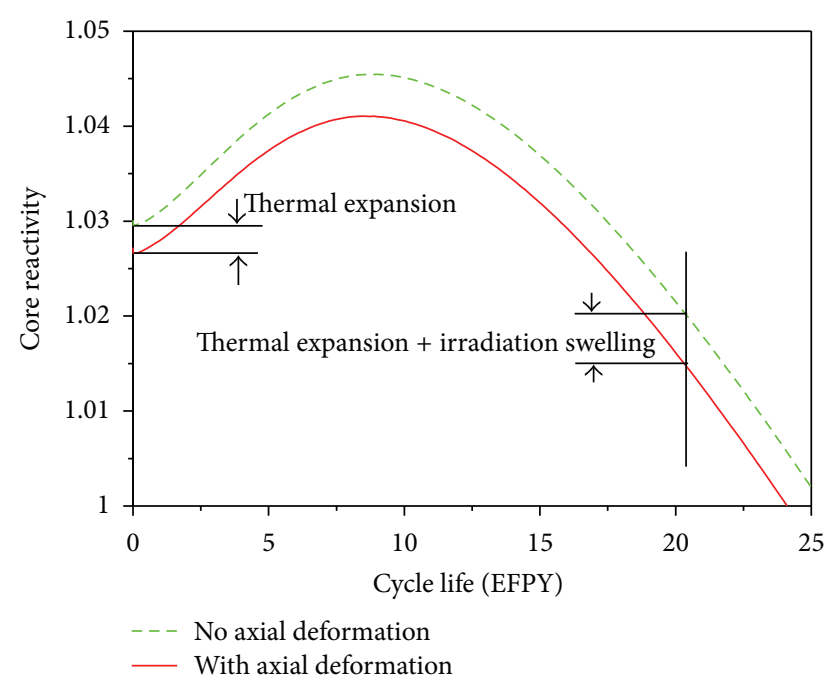

FIGURE 16: Influence of axial expansion on cycle lifetime.

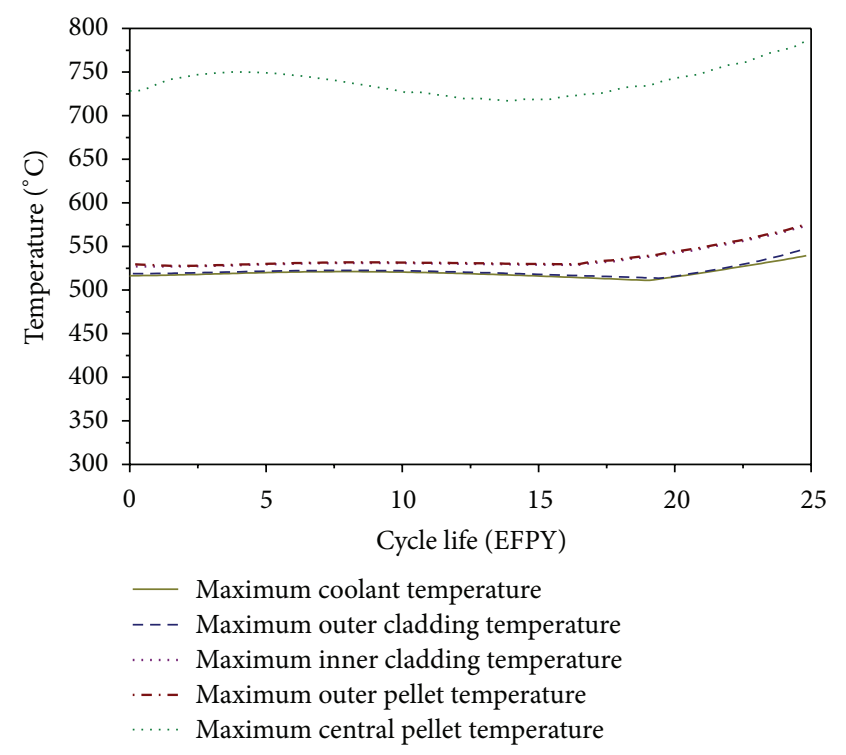

FIGURE 17: Rod peaking temperatures versus cycle lifetime.

Figure 17 shows evolution of the peaking coolant temperature and the peaking fuel rod temperatures versus the cycle life of the reference core. It can be seen from Figure 17 that each indicator has undergone an even history and maintains enough margin to their corresponding design limit, for example, the boiling point of sodium coolant is around $892^{\circ} \mathrm{C}$, while the peaking coolant temperature within the reference core cycle life is around $550^{\circ} \mathrm{C}$; the maximum operating temperature for $\mathrm{SiC}_{\mathrm{f}} / \mathrm{SiC}$ ceramic cladding is $1600^{\circ} \mathrm{C}$, while the peaking cladding temperature during cycle life of the reference core is only around $550^{\circ} \mathrm{C}$, and the molten point of metallic pellet (ternary alloy of UraniumPlutonium-Zirconium) is about $1200^{\circ} \mathrm{C}$, but the peaking fuel central temperature during the cycle life is lower than $800^{\circ} \mathrm{C}$. Therefore, the reference core of ISBBR has enough thermal margins during the whole cycle life for steady-state operation.

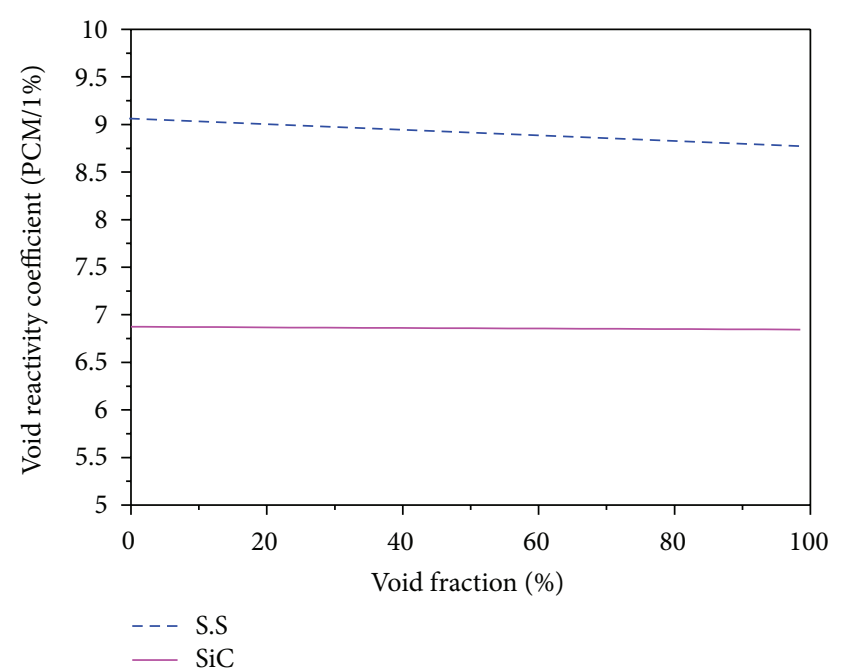

FIGURE 18: Influence of $\mathrm{SiC}_{\mathrm{f}} / \mathrm{SiC}$ on void reactivity.

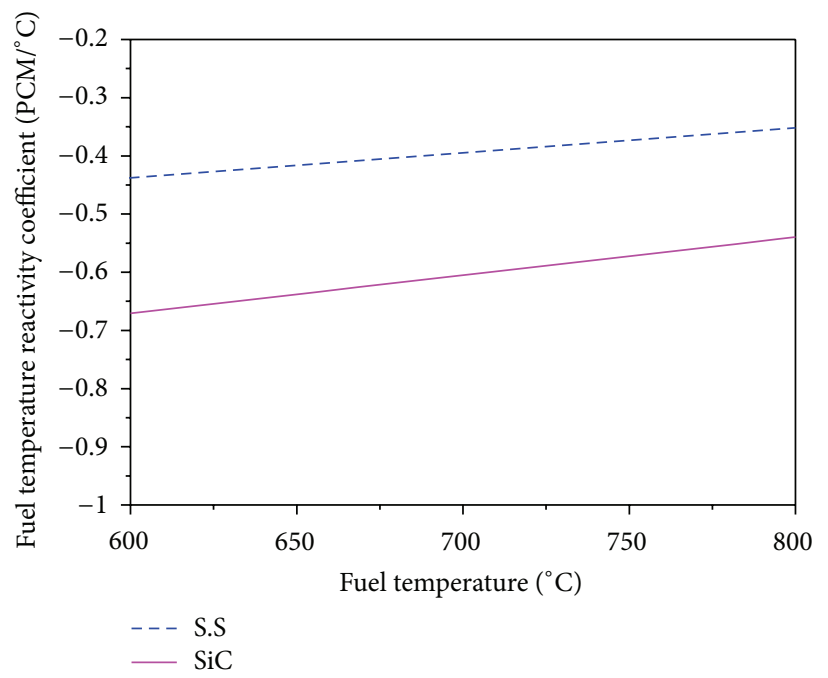

Figure 19: Influence of $\mathrm{SiC}_{\mathrm{f}} / \mathrm{SiC}$ on Doppler effect.

4.2. Transient Results Analysis. The positive Void Reactivity Coefficient and smaller Fuel Doppler Temperature Coefficient are the main characteristics of the sodium-cooled fast reactor and also the main concerns of people to the safety of the sodium-cooled fast reactor. Some studies in [12] show that the positive Void Reactivity Coefficient and smaller Fuel Doppler Temperature Coefficient may be improved if some moderator is introduced into the sodium-cooled fast reactor. Actually, $\mathrm{SiC}$ is also a kind of good moderator. Therefore, the Void Reactivity Coefficient and Fuel Doppler Temperature Coefficient of the reference ISBBR core can have significant improvement compared with the traditional SFR using stainless steel cladding, see Figures 18 and 19.

The early demonstration experiments on EBR-II had proved that the SFR using metallic fuel could safely approach lower power level during the anticipated transient without 

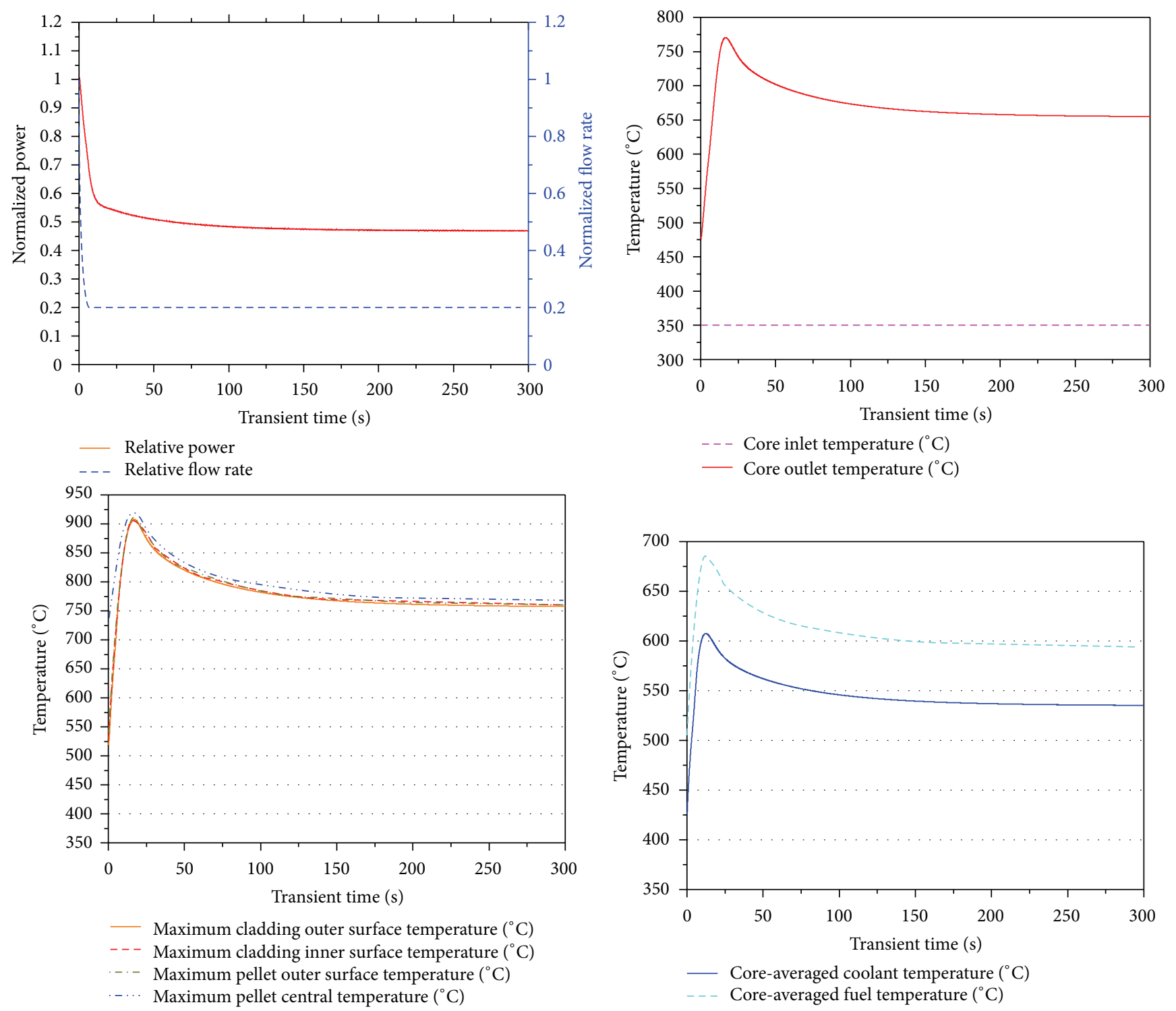

FIGURE 20: Core key parameters response during ULOFA.

scram (ATWS) [6]. The demonstration experiments on EBRII included unprotected loss of flow (ULOFA) and unprotected loss of heat sink (ULOHSA). In these two events, the initial state of the reactor was full power operation; after the transients were triggered, the reactor power was gradually decreased to lower level due to the inherent safety characteristics of neutronics and thermal-hydraulic and thermal dynamics of metallic fuel, and no damaged consequence happened, such as coolant boiling, cladding defect, or pellet molten.

TANG code is used to simulate the transient response for ULOFA and ULOHSA of reference ISBBR core. The calculated results are given in Figures 20 and 21 for ULOFA and ULOHSA, respectively. It can be seen from Figure 20 that the reactor power shall automatically decrease to $50 \%$ or so without any control assembly inserted after the flow rate rapidly reduced to $20 \%$ of the nominal value, and the peaking coolant temperature, the peaking cladding temperature, and the peaking pellet central temperature are far lower than their corresponding operation limits; similarly in Figure 21, after loss of heat sink, the core inlet temperature is rapidly increased from $350^{\circ} \mathrm{C}$ to $520^{\circ} \mathrm{C}$, and at the same time, the power level is gradually decreased to $45 \%$ or so without any protective action, and all crucial design parameters are in safe state. These analysis results demonstrate that the reference ISBBR core has inherent passive safety during typical transient processes.

4.3. Fuel Cycle Analysis. ISBBR makes use of the outstanding breeding capability of metallic fuel, produces more fissile material as consuming existing fissile material, and finally achieves ultralong cycle life and ultrahigh burnup.

Figure 22 shows the core-averaged breeding ratio of the reference ISBBR versus cycle life, and it is clear that the 

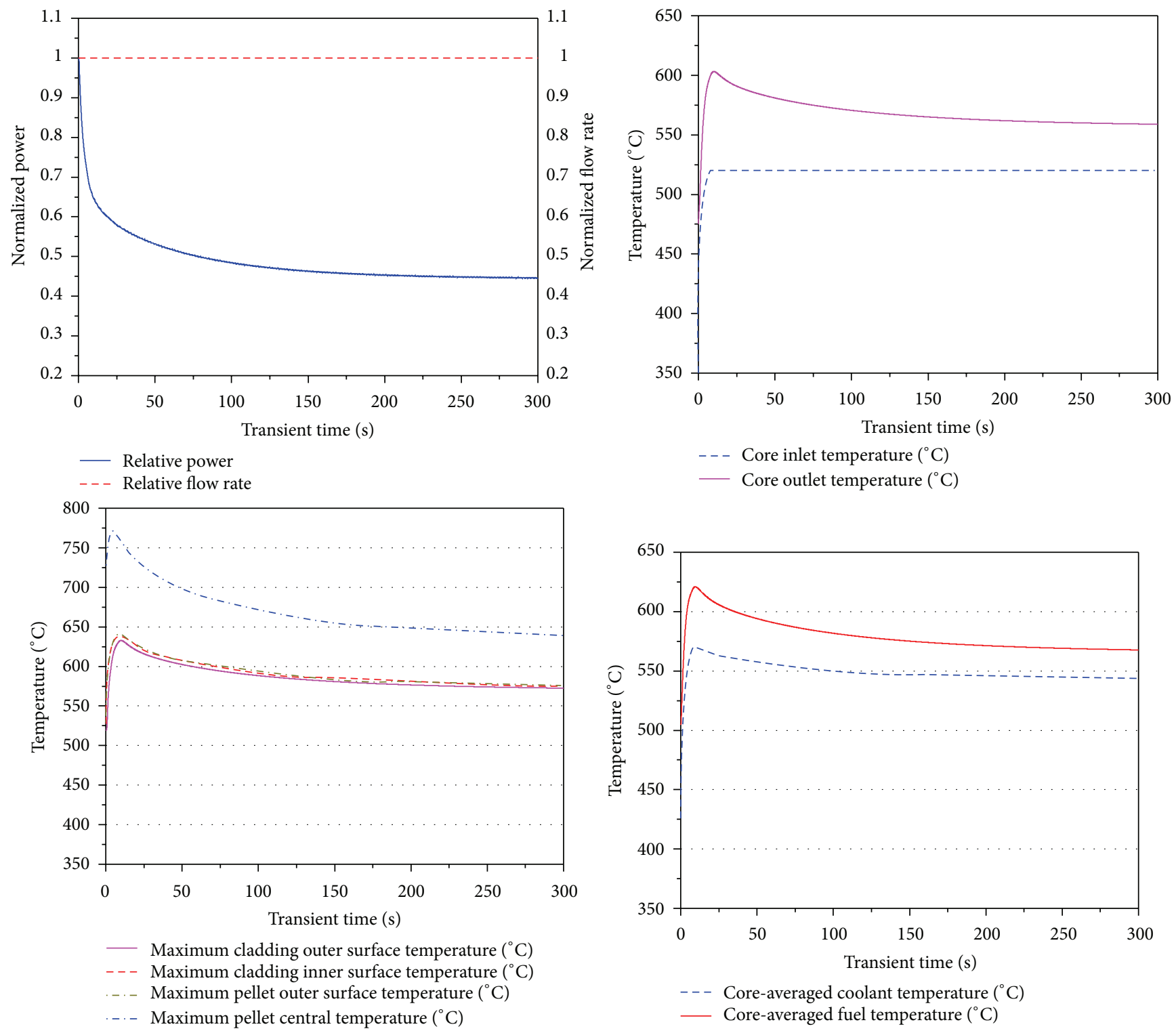

FIGURE 21: Core key parameters response during ULOHSA.

core is always breeding; the heavy metal inventory of the reference core versus cycle life is also given in Figure 22. The initial inventory of heavy metal is about 40.4 tons (including 35.8 tons of depleted uranium and 4.6 tons of Reactor Grade Plutonium), and the final inventory of heavy metal at EOL is around 33 tons, so totally there are about 7.4 tons of heavy metal burnt out, and the fuel utilization rate is about 18 at\%. Therefore, the fuel cycle economy of ISBBR is significantly improved compared with current water-cooled reactor, where the typical utilization is only $0.5 \sim 0.6$ at $\%$.

The motivation to propose ISBBR is not only to pursue safe and economical energy, but also for the following strategic prospects:

(1) continuously consume the huge volume of the depleted uranium and spent fuel accumulated by the development and deployment of water-cooled reactor, and finally achieve the minimization of the waste volume;

(2) Support sustainable development and deployment of fission energy and provide abundant and reliable energy for the peace and development of human society.

The precondition to achieve the above strategic goals is that ISBBR should implement closed fuel cycle. Fortunately, the low molten point (around $1200^{\circ} \mathrm{C}$ ) property of metallic fuel has provided a very favorable condition for economical reprocessing of spent fuel. And then, the prerequisite to achieve sustainable closed fuel cycle for ISBBR is the quantity and quality of the fission material in the spent fuel which has no degradation compared with the initial inventory. Figure 23 illustrates the evolution of plutonium inventory versus the cycle life; it can be seen that the plutonium inventory is 


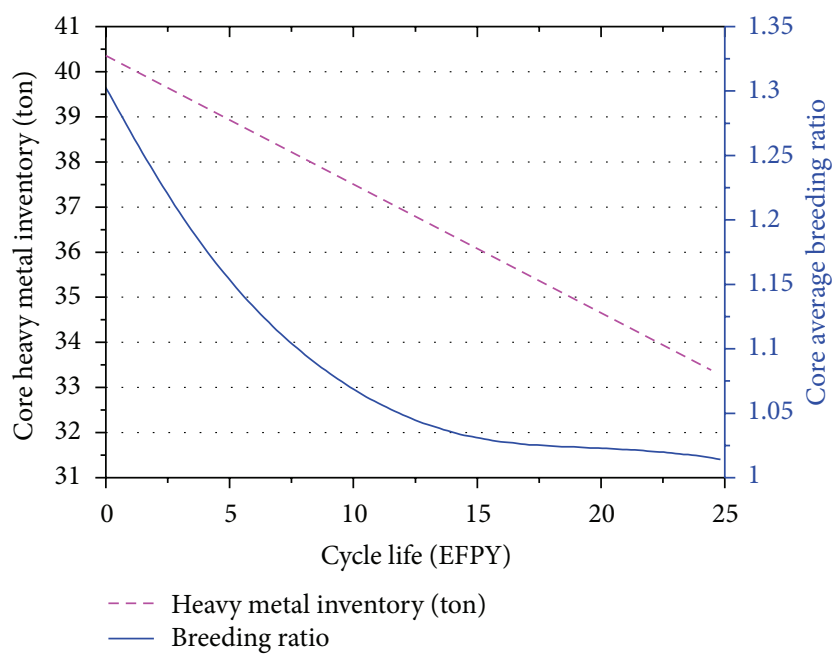

FIGURE 22: Core heavy metal inventory and breeding ratio versus cycle lifetime.

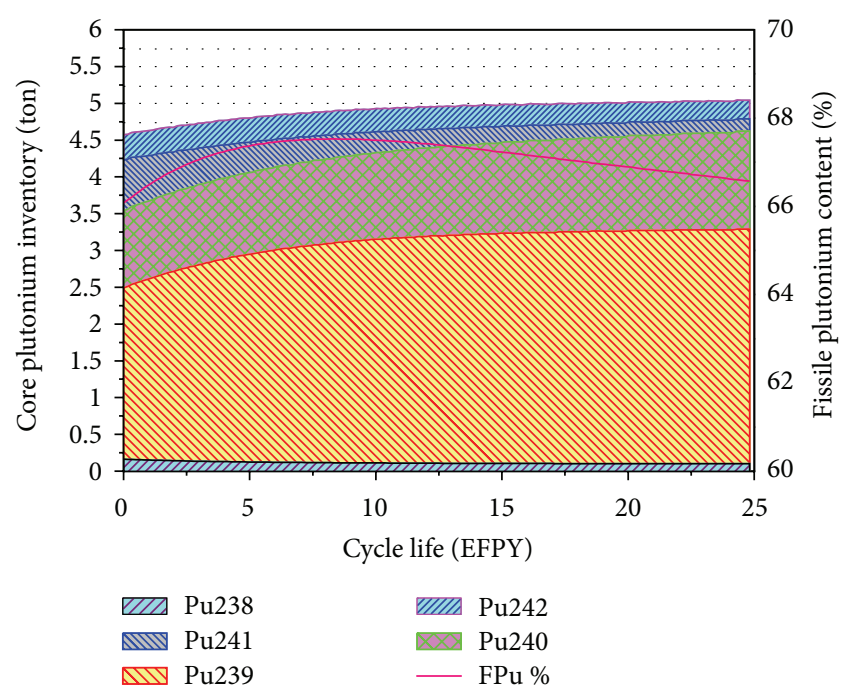

FIGURE 23: Core plutonium inventory and fissile plutonium fraction versus cycle lifetime.

increased from initial 4.3 tons to final 5.1 tons during the cycle life, the incremental is about $10 \%$, and the content of fissile plutonium $\left({ }^{239} \mathrm{Pu}\right.$ and $\left.{ }^{241} \mathrm{Pu}\right)$ in total plutonium also has been increased compared with the initial $65 \%$. Therefore, both the quantity and quality of the fission material in ISBBR spent fuel satisfy the prerequisite to maintain sustainable closed fuel cycle.

ISBBR does not pursue the accumulation or doubling of the extra plutonium, but the synchronized breeding and burning of fissile isotopes within an ultralong cycle life; therefore, it naturally satisfies the requirement of nonproliferation.

And also, only relying on the huge amount of depleted uranium and spent fuel accumulated by water-cooled reactor, ISBBR can achieve sustainable fission energy supply for long term and finally achieve the minimization of the waste volume. Let us assume that all the natural Uranium resource on the earth shall be utilized by PWR, it means that there will be about 6 million tons of depleted uranium and about 0.6 million tons of spent fuel accumulated finally; usually, the content of Reactor Grade Plutonium in the PWR spent fuel is nearly $1 \%$, so the accumulated Reactor Grade Plutonium shall be 6000 tons; taking the reference ISBBR core as an example, where the initial plutonium inventory is 4.6 tons, then, the accumulated Reactor Grade Plutonium is enough to equip 6000/4.6 $\approx 1300$ units of reference ISBBR and provides approximate $300 \mathrm{MWe} \times 1300=390 \mathrm{GWe}$ of power supply (a little higher than the current nuclear power installed capacity $377 \mathrm{GWe}$ in the world); now, the 1300 units of ISBBR shall be loaded with $1300 \times 35.8$ tons $\approx 47,000$ tons of depleted uranium and $1300 \times 4.6$ tons $\approx 6,000$ tons of Reactor Grade Plutonium for a fuel cycle, in which $1300 \times$ 7.4 ton $\approx 9600$ tons of heavy metal shall be burnt out; taking another assumption, let us ignore the $10 \%$ increment of the Reactor Grade Plutonium in spent fuel and think it is used to compensate for the loss during spent fuel reprocessing and the new fuel fabrication, then, the time for these 1300 units of ISBBR to consume the accumulated 6 million tons of depleted uranium can be approximately estimated as follows:

$$
\begin{aligned}
& \frac{6000000+(600000-6000)-(47000+6000)}{9600} \times 25 \text { year } \\
& \approx 17000 \text { years. }
\end{aligned}
$$

Humans, of course, may not need 17,000 years of fission energy supply; in turn, they may want to have much more installed capacity. In this case, people can have some breeder reactors in earlier stage and produce Reactor Grade Plutonium, and then, they can get their wanted installed capacity by building enough units of ISBBR. Even if the number of ISBBR unit was increased to 13,000 units, the accumulated 6 million tons of Depleted Uranium still can support over 1000 years of nuclear power supply.

\section{Conclusion}

Based on the platform of traditional sodium-cooled fast reactor, making use of the innovative fuel design and core design, ISBBR can achieve ultralong cycle and ultrahigh burnup and maintain stable radial power distribution during the cycle life without refueling and shuffling.

Primary calculation results, provided by specifically developed computer code TANG, demonstrate that the ISBBR core has enough thermal margins during steadystate operation and inherent passive safety during anticipated transients.

The fuel cycle analysis indicates that the fuel utilization rate of ISBBR can approach $18 \%$ and have significant fuel cycle economy compared with the current water-cooled reactors, where fuel utilization is about $0.5 \sim 0.6 \%$.

In addition, the features of ultralong cycle, no extra plutonium accumulation, and sustainable closed fuel cycle demonstrate that ISBBR can realize the minimization of waste volume, nonproliferation, and sustainable nuclear power supply. 
In conclusion, ISBBR can well satisfy the requirements of Gen-IV nuclear energy system, such as sustainability, economy, safety, and nonproliferation and has a great development potential.

\section{References}

[1] IAEA/NEA/OECD, Uranium2009: Resources, Production and Demand, IAEA/NEA/OECD, 2010.

[2] World Nuclear Association, The Global Nuclear Fuel Market: Supply and Demand 2011-2030, World Nuclear Association, London, UK, 2011.

[3] R. H. Jones, D. Steiner, H. L. Heinisch, G. A. Newsome, and H. M. Kerch, "Radiation resistant ceramic matrix composites," Journal of Nuclear Materials, vol. 245, no. 2-3, pp. 87-107, 1997.

[4] S. Si, "3D coarse mesh NEM embedded with 2D fine mesh NDOM for PWR core analysis," in Proceedings of the Advances in Reactor Physics to Power the Nuclear Renaissance Conference (PHYSOR '10), pp. 257-268, Pittsburgh, Penn, USA, May 2010.

[5] S. Si, "Algorithm development and verification of UASCM for multi-dimension and multi-group neutron kinetics model," in Proceedings of the Advances in Reactor Physics ConferenceLinking Research, Industry, and Education (PHYSOR '12), Knoxville, Tenn, USA, April 2012.

[6] S. H. Fistedis, Ed., The Experimental Breeder Reactor II Inherent Safety Demonstration, vol. 101 of Nuclear Engineering and Design No. 1, North-Holland, New York, NY, USA, 1987.

[7] R. G. Pahl, D. L. Porter, D. C. Crawford, and L. C. Walters, "Irradiation behavior of metallic fast reactor fuels," Journal of Nuclear Materials, vol. 188, pp. 3-9, 1992.

[8] T. Ellis, R. Petroski, P. Hejzlar et al., "Traveling-wave reactors: a truly sustainable and full-scale resource for global energy needs," in Proceedings of the International Congress on Advances in Nuclear Power Plants (ICAPP '10), Paper 10189, pp. 13-17, San Diego, Calif, USA, June 2010.

[9] G. J. van Tuyle, G. C. Slovik, B. C. Chan, K. J. Kennett et al., "Summary of advanced LMR evaluation-PRISM and SAFR," Tech. Rep. NUREG/CR-5464, 1989.

[10] Y. I. Chang, P. J. Finck, C. Grandy et al., "Advanced burner test reactor preconceptual design report," Tech. Rep. ANL-ABR-1, 2006.

[11] T. K. Kim and T. A. Taiwo, "Feasibility study of ultra-long life fast reactor core concept," in Proceedings of the Advances in Reactor Physics to Power the Nuclear Renaissance Conference (PHYSOR '10), pp. 1756-1766, Pittsburgh, Penn, USA, May 2010.

[12] B. Merk, "On the effect of different placing $\mathrm{ZrH}$ moderator material on the performance of a SFR core," Annual of Nuclear Energy, vol. 38, pp. 2374-2385, 2011. 


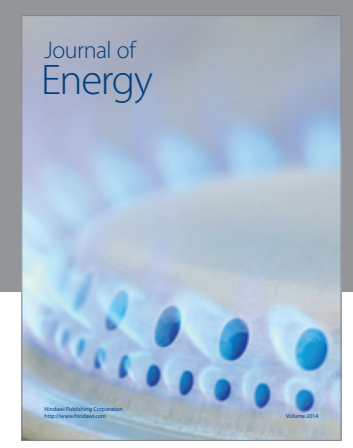

Journal of

Industrial Engineering
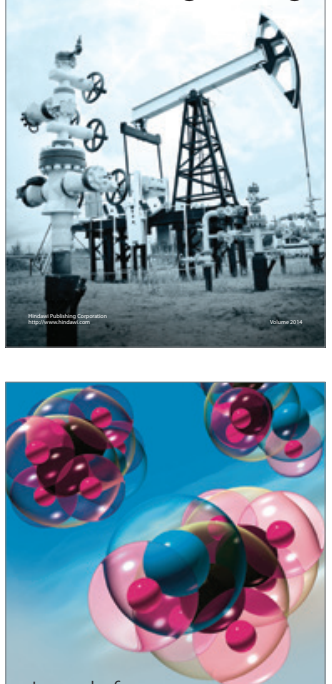

Fuels
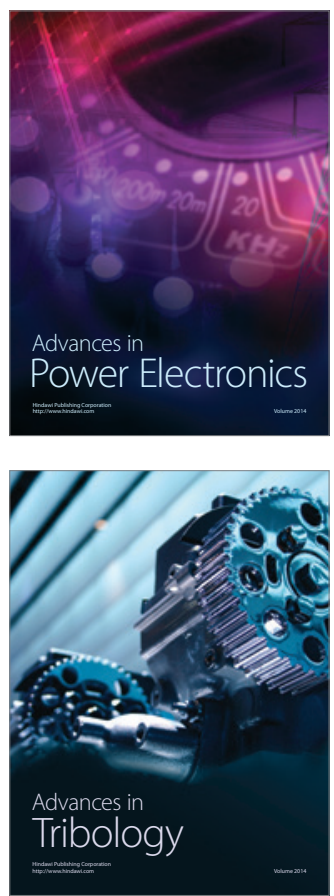

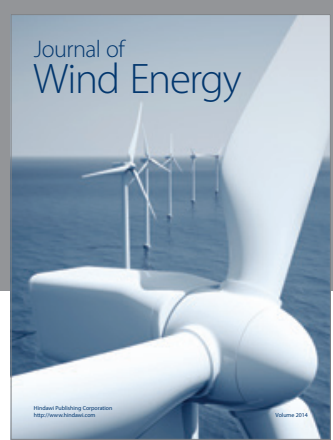

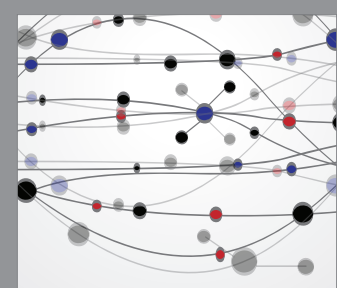

The Scientific World Journal

Submit your manuscripts at http://www.hindawi.com

Journal of

Structures
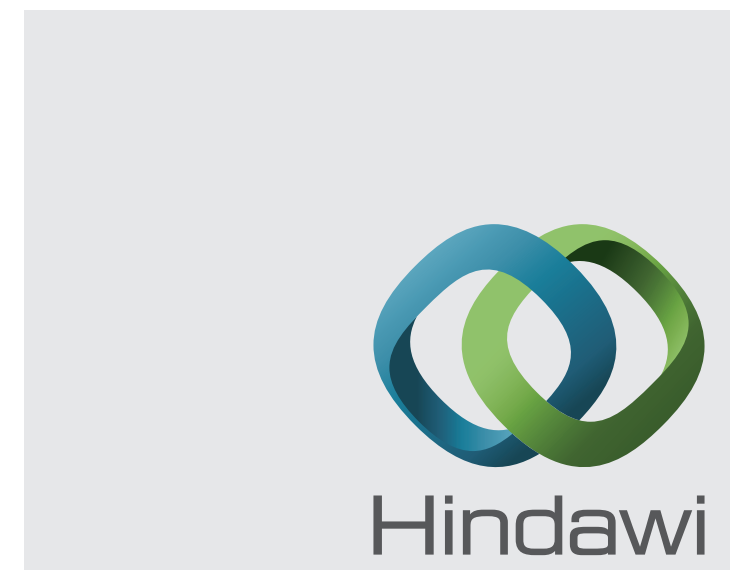

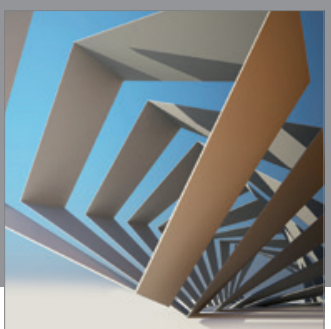

Rotating

Machinery
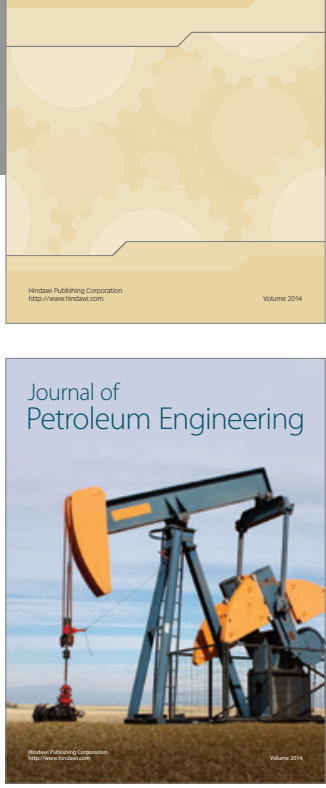

Journal of

Solar Energy
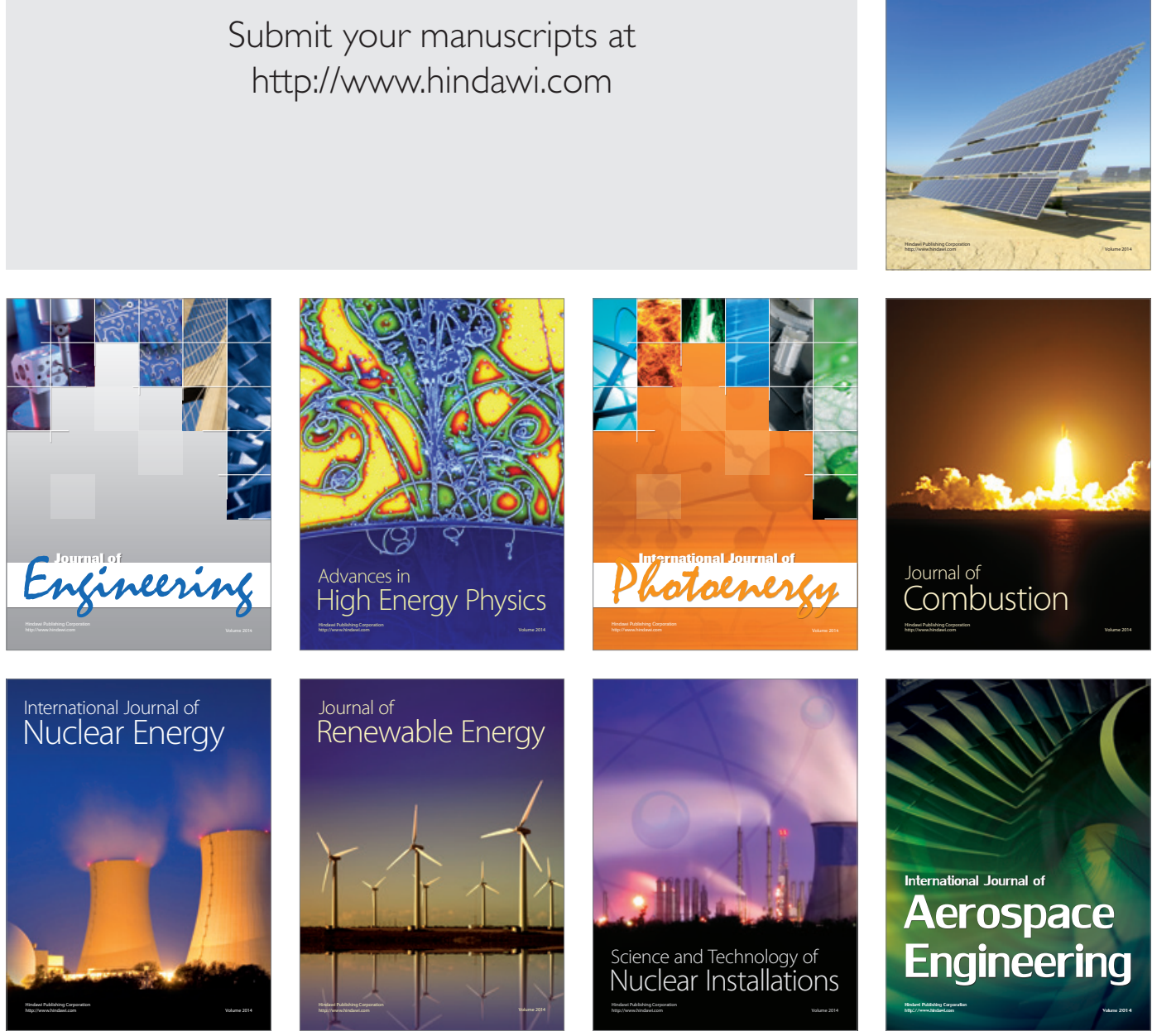